\title{
Plataforma de monitoria online
}

\author{
Lucas Abreu da Silva ${ }^{1,2}$, Esteic Janaina S. Batista ${ }^{1,2}$, Gabriela Camargo Pacher ${ }^{3}$, \\ Amaury A. Castro Jr. ${ }^{1,2}$ \\ ${ }^{1}$ Universidade Federal de Mato Grosso do Sul - Campus Ponta Porã (CPPP) \\ Rua Itibiré Vieira, s/n - Residencial Julia Oliveira Cardinal BR 463 - Km 4,5 \\ ${ }^{2}$ Bolsistas do Programa de Educação Tutorial - PET/SESu/MEC \\ ${ }^{3}$ Instituto Federal de Mato Grosso d Sul - Campus Ponta Porã (CPPP) \\ Rodovia BR-463, km 14, s/n
}

\{lucasabreudasilva, esteicejanaina, gabrielacpacher, amaury.ufms\}@gmail.com

Abstract. Monitoring programs in higher education institutions has an important role, contributing to the reduction of evasion in courses and the training of students and also for the avoidance of ameliorating the courses. This tool enables students improve their knowledge in a particular discipline and, moreover, enables the exchange of experience between academics who have more difficulties with those with more ease. This paper presents an online monitoring platform that can be used in different disciplines as a way to mediate in the process of teaching and learning, the relationship between monitor and student.

Resumo. A monitoria nas IES desempenha um importante papel no que diz respeito a ser um dos fatores que podem contribuir para a formação profissional dos estudantes e, também, para a amenização da evasão nos cursos. Essa ferramenta possibilita que os acadêmicos aprimorem seus conhecimentos em determinada disciplina e, além disso, possibilita a troca de experiência entre os acadêmicos que apresentam mais dificuldades com aqueles que possuem mais facilidade. Este trabalho apresenta uma plataforma de monitoria online que pode ser utilizada em diferentes disciplinas, como forma de mediar, durante o processo de ensino-aprendizagem, a relação entre monitor e estudante.

\section{Introdução}

A monitoria é um dos importantes papéis que o estudante pode desempenhar durante sua graduação em uma Instituição de Ensino Superior (IES), regulamentada no artigo 24 da Lei Federal n. ${ }^{\circ}$ 9394, de 20 de dezembro de 1996.

O monitor, por meio da sua prática docente, melhora seu aprendizado e suas experiências acadêmicas, tornando-se cada vez mais próximo de desempenhar um papel acadêmico na instituição [Medeiros 2011]. Por outro lado, o aluno que procura o recurso da monitoria, dentro da instituição, consegue tirar dúvidas de determinado conteúdo, principalmente em disciplinas cursadas no início do curso, considerando a base de conhecimento com a qual os estudantes chegam ao Ensino Superior. Tal base e/ou preparo, algumas vezes, não se faz suficiente para compreender e acompanhar os 
conteúdos ofertados na grade curricular, mesmo aqueles que constituem a parte introdutória, sendo um dos principais elementos que causam evasão no início dos cursos [Barroso e Gomes 2016]. Além disso, a monitoria também pode ser adotada como uma alternativa dinâmica para o estudante aprofundar-se nos assuntos apresentados em aula.

No entanto, um dos motivos que impedem ou dificultam a participação destes estudantes em atividades de monitoria estão relacionados à falta de tempo. Em alguns cursos, como da área de informática, muitos já trabalham ou conseguem estágio desde os primeiros períodos do curso, prejudicando a procura pelos monitores e suas respectivas contribuições. Neste contexto, o uso de recursos online, mediados pelo $e$ learning, tornam-se necessários para romperem as barreiras do tempo e do espaço, descomplicando a troca de conhecimento entre monitor e estudante.

Outros pesquisadores como [Fernandes 2011] já demonstraram a importância da tutoria online e o uso de outras plataformas para este fim, nos quais nos baseamos para a o desenvolvimento deste trabalho.

O objetivo é apresentar uma plataforma online de monitoria, que surgiu a partir destes empecilhos encontrados pelos monitores e estudantes dentro de uma IES, que permite ser utilizado em qualquer disciplina.

\section{A plataforma}

A plataforma foi desenvolvida na linguagem PHP, utilizando banco de dados MYSQL e pode ser utilizada virtualmente, propiciando o contato à distância com o monitor. É dividida em dois principais módulos: a página do estudante e a página do monitor. Para utilizar a plataforma é necessário que o monitor requisite a hospedagem da mesma em um servidor de arquivos com um domínio específico. Por existir hospedagens e domínios gratuitos, não existe nenhum custo na plataforma. Após hospedado e configurado, estará disponível para uso sendo, até o momento, exclusivo para Web.

\subsection{Página do Estudante}

A Página do Estudante (Figura 1) apresenta dois campos de formulário, onde serão informados a pergunta (dúvida) e o correio eletrônico para ser enviada ao monitor. A interface também contém informações básicas sobre a disciplina, como nome, monitor, local da monitoria física e endereço de acesso à página de arquivos compartilhados e, por último, perguntas frequentes, listando as principais dúvidas dos estudantes na disciplina.

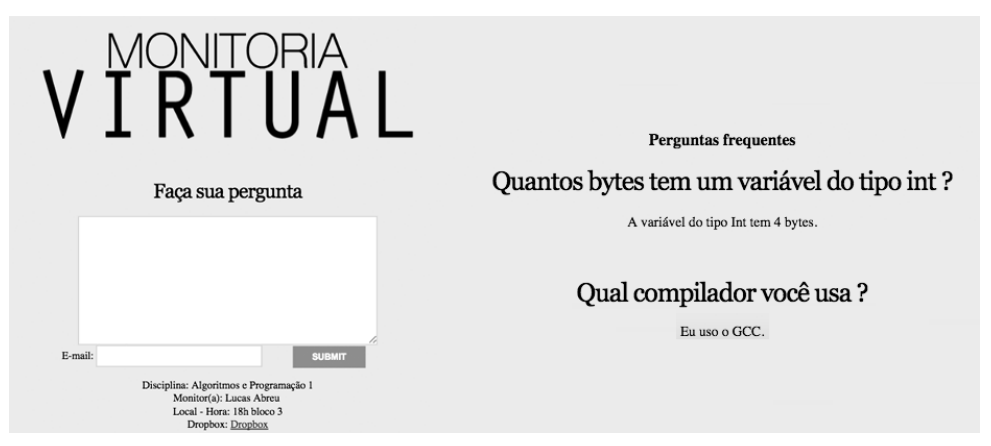

Figura 1. Página do Estudante 
V Congresso Brasileiro de Informática na Educação (CBIE 2016)

Anais dos Workshops do V Congresso Brasileiro de Informática na Educação (CBIE 2016)

O diagrama de sequência da aplicação está descrito no diagrama de sequência (Figura 2). Não existe cadastro de estudantes na plataforma, sendo a página de acesso livre pelos estudantes.

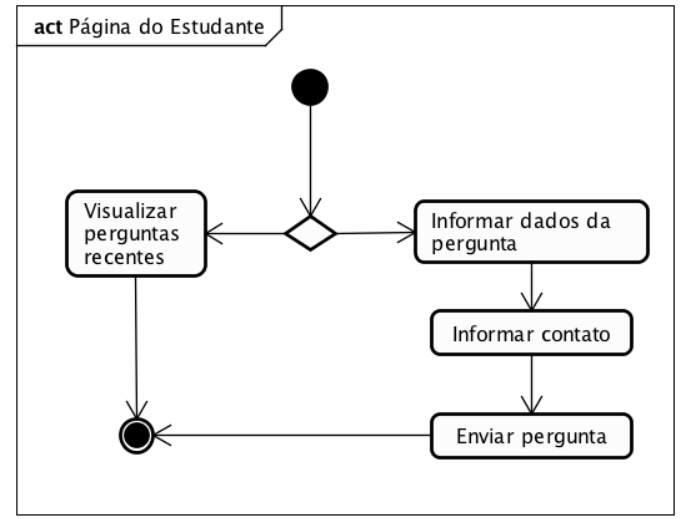

Figura 2. Diagrama de sequência da aplicação - Módulo do estudante.

\subsection{Página do Monitor}

Para acessar a página do Monitor (Figura 3), o monitor deverá ter um usuário e senha cadastrados no banco de dados da plataforma. A plataforma possui capacidade para cadastro de múltiplos monitores.

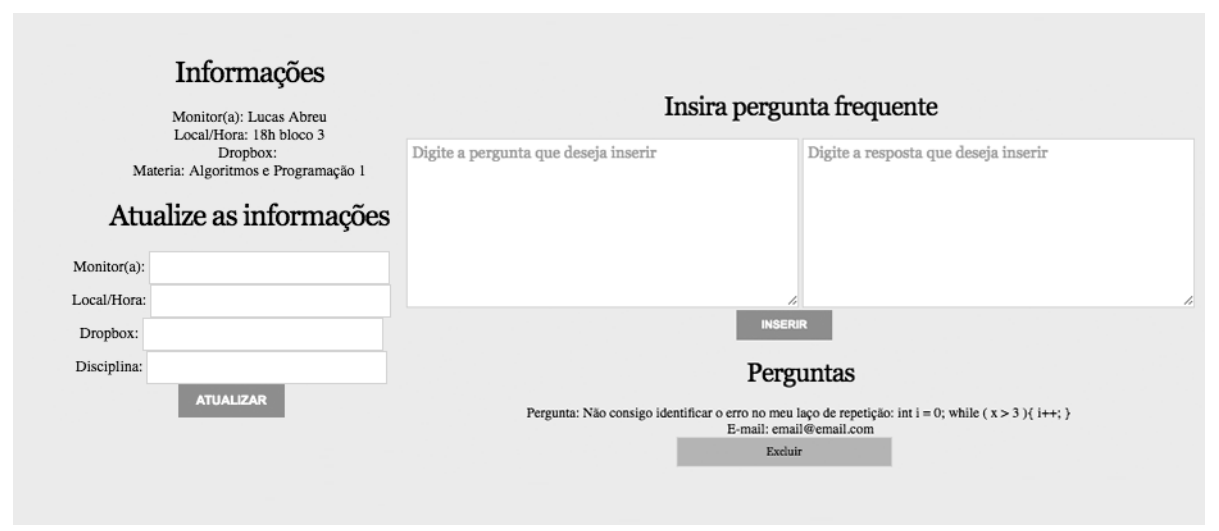

Figura 3. Página do Monitor

Após efetivado o acesso do usuário, serão mostrados os seguintes campos: Informações, Atualização de Informações, Inserção de Perguntas Frequentes e Perguntas enviadas pelos usuários. As questões inseridas nas perguntas frequentes serão visíveis a todos os estudantes que acessarem a plataforma. $\mathrm{O}$ diagrama de sequência da aplicação está representado no diagrama da Figura 4. 
V Congresso Brasileiro de Informática na Educação (CBIE 2016)

Anais dos Workshops do V Congresso Brasileiro de Informática na Educação (CBIE 2016)

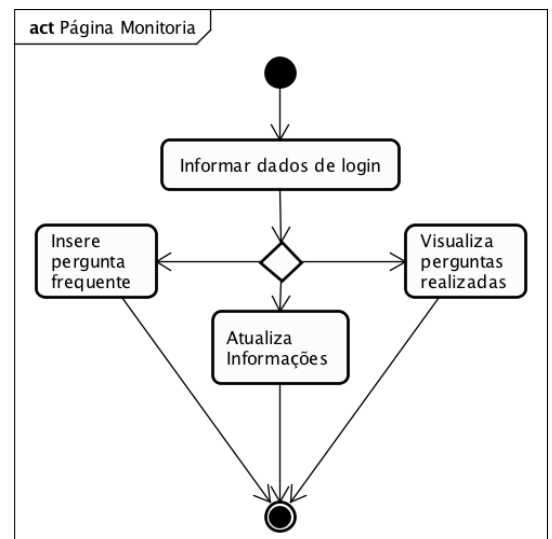

Figura 4. Diagrama de sequência da aplicação - Módulo do monitor

\section{Considerações Finais}

A plataforma foi desenvolvida recentemente e está sendo utilizada por quatro monitores no período de um semestre em quatro disciplinas. Dados quantitativos e qualitativos serão coletados por meio de questionários e depoimentos desses sujeitos que exploraram, direta e indiretamente, a plataforma no término das disciplinas. Estas observações permitirão que outras funcionalidades e melhorias no layout sejam realizadas a partir das opiniões dos usuários.

Pretende-se implantar alguns aperfeiçoamentos com base nas críticas construtivas informadas pelos monitores, estudantes e professores das disciplinas presentes na monitoria virtual. Essas sugestões podem incluir, por exemplo, o contato dos estudantes com os monitores por meio de notificações feitas pelo correio eletrônico, o acesso dos estudantes a perguntas e respostas realizadas por outros estudantes - com anonimato do nome ou não -, a integração com aplicativos móveis e a possibilidade de anexar arquivos nas perguntas e respostas, dentre outros. Além destes, funcionalidades que permitam os professores, quando necessário, acompanharem e intervirem nas atividades da monitoria.

\section{Referências}

Barroso, I., e Gomes, C. H. (2016). A importância das monitorias no Ensino Superior e seu papel na diminuição da evasão. Anais do Salão Internacional de Ensino, Pesquisa e Extensão, 7(1).

Fernandes, R. R; Fernandes, A. P. L. M e Santos, S. (2011). Tutoria On Line: uma Maneira Prática, Fácil e Divertida de Aprender. Anais do Simpósio de Excelência em Gestão e Tecnologia.

Lei $\mathrm{n}^{\circ}$ 9.394, de 20 de dezembro de 1996. (1996, 20 de dezembro). Estabelece as diretrizes e bases da educação nacional. Presidência da República. Brasília. Disponível em: http://www.planalto.gov.br/ccivil_03/LEIS/L9394.htm\#art80. Acesso em 26 de junho de 2016.

Medeiros, F. P. A. e Gomes, A. S. (2011, Novembro). Implantação de um Modelo de Monitoria Virtual Apoiado pela Plataforma de Gerenciamento de Aprendizagem Amadeu. Anais do Workshop de Informática na Escola (p. 1444). 